\title{
EDITORIAL
}

\section{Nutrient bandwagons}

Studying the older nutritional literature is intriguing and often humbling. One cannot help noticing how much nutritional research seems to follow fashions, in a research sense, in that one finds a cluster of work around a particular topic which in many instances fades away only to reappear as another generation of researchers picks-up the topic again. Sometimes one can see a good reason for the rise and fall of a research area. Perhaps a technological barrier has been met and the topic has to be put on hold until new techniques arise and move the subject forward. The study of energy balance and its regulation is one such topic where the limitations of indirect calorimetry in the field using portable gas meters put a limit on further progress and had to wait for doubly-labelled water to move the area back into the research frame. Alternatively, a new concept may act as the stimulus; thus work on energy balance and its regulation was also influenced by the new ideas introduced, almost as a heresy, by Derek Miller and Pamela Mumford about the efficiency of the energetic processes, which led to some elegant studies of the biochemistry of adipose tissue which is now being given a further burst of life with the application of molecular biological techniques.

Looking back over the past 25 years in the British Journal of Nutrition I was struck by how the papers seem to focus on a nutrient and develop as a nutrient 'bandwagon' or, possibly more accurately, a 'honey pot'.

My impression is that these bandwagons are becoming more powerful determinants of the fashionable in nutrition research, possibly because a research area has been identified as having some special merit and warrants priority, so that the attraction is the availability of funding. We are talking about 'money' pots rather than 'honey'.

One can have few doubts about the careful way that forward priorities are assessed and the decisions taken, although in some cases the care taken over reviewing the evidence may mean that the research area has moved on or become less attractive to the innovative researcher in the meantime. One does sometimes wonder whether the very existence of a honey pot leads to proposals that are not well-founded but have been put together simply because the funds exist, and no one should criticize a researcher for seeking funds where there is a likelihood they exist. However, we do see occasional papers where the work is based on a rather implausible hypothesis and one gets the impression that it was started because it included some key 'buzz-words' mentioned in some priority document. Such work is often worthy but often lacks the sparkle of work that was conceived as a research hypothesis which interested the researcher rather than a committee somewhere.

Occasionally these nutrient bandwagons can have wider consequences outside the nutritional sciences. Thus one finds extrapolations of a valid scientific hypothesis being promoted in the wider world. For example, in a recent Editorial in the American Journal of Clinical Nutrition the promotion of antioxidant supplements as protective agents came in for some severe criticism from Victor Herbert. Research on antioxidants was actively represented in the British Journal of Nutrition 25 years ago but then it was a fairly lone furrow being worked by a few groups.

Dietary fibre was another type of nutrient bandwagon which happily is still rolling gently along. This was started in a different way, almost because the general public accepted the 
hypothesis regarding the protective effects and forced the priority onto the food scientist who, together with a few nutritionists with clinical connections, thought that the whole idea was too good to be true and set out to test and evaluate the hypothesis, often with refutation as their primary objective.

I suppose that research will always have its fashions dictated by technical possibilities, plausible hypotheses or the accolade of priority for funding. Hoping for the millennium when nutrition research could be an hypothesis-driven integrated scientific discipline will not, as they say, 'pay the mortgage'. I do however believe that we need to be sure scientifically that 'honey pots' do not become honey traps and lead nutritional research into fashionable areas which do not lead to an improved understanding of the nutritional sciences.

D. A. T. SOUthGate

\section{REFERENCE}

Herbert, V. (1994). The antioxidant supplement myth. American Journal of Clinical Nutrition 60, 157-158. 